\title{
The Promises and Perils of Hospital Mergers
}

\author{
Jonathan Daigle \\ Monmouth University \\ Michaeline Skiba \\ Monmouth University
}

Over the course of several decades, mergers have been regular occurrences within the business sector. Since healthcare is an industry, it is common knowledge that hospitals -for better or worse-have not been immune from this business-driven phenomenon. Utilizing select sources from both the management and financial literature, this paper will briefly examine how and why hospital mergers have occurred and changed, how they have achieved or failed their intended purposes, and some of the potential obstacles that may surface in existing and future healthcare consolidations that include hospitals and other provider groups. Consequently, solid evidence must be made available to prove that current and future mergers deliver what they promise - namely, clear communications, quality care outcomes, and reduced costs.

Keywords: hospitals, healthcare, mergers, quality

\section{INTRODUCTION}

Almost a decade ago, Jonas and Kovner (2011) identified two approaches to ensure the survival of hospitals. The first approach stressed the need to reimburse hospitals for all types of patient care that resulted in payments approximating actual costs. At that time, only "big ticket" procedures such as heart surgeries and technologically advanced interventions represented a small profit versus all other patient care services that incurred losses. Not surprisingly, their second approach was the closing or merging of some hospitals. While they acknowledged the government's role in keeping hospitals open during hospital downturns, these authors also noted how that timeframe's economic environment made such interventions less likely to happen. They cautioned healthcare managers with the following: "Closings - always controversial in a local area - likely will happen, but they can happen responsibly, so that the closure does not threaten the capacity of a community's health system to meet residents' inpatient needs" (Jonas and Kovner, 2011, p. 362-363).

The aforementioned authors could not have predicted what happened only a few years later: both massive and nationwide hospital consolidations and concurrent increases in healthcare costs.

"From 2013 to 2017, nearly 1 in 5 of the nation's 5,500-plus hospitals were acquired or merged with another hospital, according to Irving Levin Associates, a health care analytics firm in Norwalk, Conn." (Findlay, 2018, p. 2). Furthermore, for-profit hospitals will grow more rapidly as they buy both for-profits and non-profits, many of which exist to provide public health services to their communities. "In 2017, 29 
for-profit companies bought 11 not-for-profits and 18 for-profit hospitals, according to [another] Irving Levin Associates analysis for Kaiser Health News" (Findlay, 2018, p. 3).

The current and continued uptick in hospital consolidations fundamentally requires a serious examination of three factors that demonstrate discernible impacts on the delivery of healthcare. These factors are culture, quality, and cost.

\section{MANAGEMENT ISSUES}

\section{Culture}

Arguably, organizational culture is a factor that is often overlooked or minimized when hospital mergers occur. In most workplaces, an organization's values exert a powerful influence on the ways in which internal stakeholders (managerial and non-managerial employees, owners) and external stakeholders (current and prospective patients-consumers, constituents within the broader community) perceive and react to organizational change. If individuals' values and organizational values are misaligned, anticipated outcomes may be difficult to achieve. According to one source, the definition of a corporate culture is "a set of values, norms, and artifacts, including ways of solving problems that members (employees of an organization) share" (Ferrell, Fraedrich, and Ferrell, 2018, p. 120). It appears clear that merging two or more healthcare entities creates dramatic and potentially disruptive changes that affect not only employees but also everyone involved in the restructured and larger entity.

McKinsey \& Company surveyed 3,199 leaders to learn whether change management programs within their organizations were successful and only one-third of them said that they were (Dewar and Keller, 2009; Kaetzler, Kordestani, O'Loughlin and Van Oostende, 2019). In a more extensive McKinsey study that examined ten years of data collected from merger and acquisition (M\&A) executives, “...organizational issues like cultural differences and changed operating models account, on average, for almost 50 percent of the failure of mergers to meet expectations" (Kaetzler et al., 2019, p. 1), and it was noted that executives often do not attend to these issues until they surface after a reorganization takes place.

Executives are primarily concerned about cultural changes affecting productivity and profitability. Realistically, though, the values, norms, artifacts and problem-solving changes as noted earlier and that are affected by a hospital merger can wreak a multitude of problems prior to the achievement of executives' expectations. For example, work-related activities that involve all employees include but are not limited to changes in roles and responsibilities, work processes, reporting structures, and both long-term and shortterm decision-making. Apart from work functions, personal and interpersonal ramifications can include stress, anxiety, and emotional detachment from former and new peers and supervisors. Not surprisingly, these behavioral traits potentially erode a sense of trust in leadership, affect turnover, and influence external stakeholders' perceptions of the new/combined organization.

Decades ago, an article entitled "Surviving a Merger" appeared in the journal Nursing. At that time, hospital mergers consisted mostly of one hospital merging with another one versus the more complex, multitiered hospital system structures that have evolved since that time. The authors suggested a number of ways that employees could use to minimize stress, and these included keeping a journal of personal thoughts and feelings; taking care of yourself by finding and giving support to others; and acknowledging the culture changes (Katz and Clemons, 1995). As will be seen in the next sections of this paper, most of this wellintentioned advice has become increasingly more difficult to follow as hospital mergers have included more than hospitals.

\section{Quality}

According to various doctors, attorneys and academicians, bigger may not be better and better quality of patient care is questionable. Although some hospital CEOs and Presidents tout the promises of lowered costs and improved care as results of hospital mergers, others offer compelling evidence to the contrary.

For several years, the trend toward vertical healthcare mergers has escalated. Frakt cited a 2012 research literature study conducted under the aegis of the Robert Wood Johnson Foundation. The study found that, in general, "...hospital consolidation leads to higher prices (often exceeding $20 \%$ in very concentrated 
markets) and reduces quality" (Frakt, 2015, p. 345). Two years later, the same Foundation published a report to Congress that stressed how healthcare regulations have affected physicians' practice choices. Citing Medicare reimbursement regulations, the report explained how hospital physicians who are employed and practice in hospital outpatient departments receive much higher payments than physicians practicing independently in their own offices (Robert Wood Johnson Foundation, 2014).

Similarly, other researchers have found that hospitals have increased their number of employed physicians in certain specialties to take advantage of Medicare's discounted outpatient drug pricing for qualifying entities (Desai and McWilliams, 2018). In an examination of physician practices acquired in hospital acquisitions, other researchers found an average $14.1 \%$ increase in pricing for services provided post-acquisition. In addition, "price increases are larger when the acquiring hospital has a larger share of its inpatient market" and "...integration of primary care physicians increases enrollee spending by $4.9 \%$ " (Capps, Dranove and Ody, 2018, p. 139). How and to what extent these physician arrangements continue to positively or negatively affect the quality of and access to clinical care and treatment options for patientsconsumers remains questionable.

In addition to the absorption of physician groups, the vertical merger trend can also include the acquisition of large pharmacy chains and pharmacy benefit management (PBM) companies, and this activity raises concerns. Does the sheer market power of a vertically integrated healthcare provider affect the quality of pharmaceutical treatments that patients-consumers receive? One researcher has a partial answer as follows: "a pharmacy chain could develop formularies for rivals that do not include important drugs that are in demand by their subscribers or offer pharmacy networks that do not provide important pharmaceutical distribution options to rival subscribers" (Greaney, 2018, p. 920). Thus, financial or physical access to certain medications can potentially inhibit treatment and recovery outcomes for patientsconsumers.

A recent study from Rice University's Baker Institute for Public Policy showed little to no improvements in care quality after a vertical merger. The study's data were gleaned from the CMS Hospital Compare database on more than 4,400 hospitals from 2008 to 2015, and for the majority of quality of care measures, physician-hospital integrations did not improve these measures. One of the authors of the study, Vivian Ho, James A. Baker III Institute Chair in Health Economics and Director of the Institute's Center, stated that "The government requires that hospitals report on a wide variety of quality measures, such as practice of preventive care for surgical patients, whether their doctor or nurse communicated well, or whether the patient would recommend the hospital to others" (LaPointe, 2019, p. 1). The lowest rated measure in this study was patient satisfaction. Short and Ho (2020) explain this rating as follows: "Although better patient experience may not always correlate with higher clinical quality, measuring quality based on patient perception is increasingly important as more consumers use online physician ratings and reviews of patient experience to select providers."

The closure of rural hospitals is another concern related to the quality of care (and access) conundrum. According to the U.S. Government Accountability Office (GAO), 64 rural hospitals closed from 2013 through 2017, representing approximately three percent of all rural hospitals in 2013 and more than twice the number of closures of the prior five-year period (U.S. Government Accountability Office, 2018). As vertical mergers continue to consolidate more medically-related entities in suburban and metropolitan locations, one wonders how rural patients- consumers - many of whom are poor Medicare and Medicaid recipients - will be treated.

\section{FINANCIAL ISSUES}

\section{Costs}

Economies of scale have the potential to greatly reduce operating costs. However, the reduction in costs does not necessarily translate to price decreases for patients. Unfortunately, the literature documents a lack of correlation between hospital systems and pricing. Melnick and Keeler (2007) find this relation when studying the price trends of California hospitals during the 1999-2003 period. They observe hospitals systems are more likely to raise prices relative to independent hospitals. Hospitals within large (small) 
systems increase their prices by $34 \%$ (17\%) relative to independent hospitals. Cooper et al. (2018) expand upon Melnick and Keller by examining the effects of market concentration on hospital prices across the entire United States. They observe monopoly hospitals (as measure by the Herfindahl-Hirschman index) have prices that are $12 \%$ higher than markets with four or more competitors.

Studies focusing on merger activity find similar results. In the same study, Cooper et al. analyze 366 mergers and acquisitions over the 2007-2011 period. They observe mergers result in a $6 \%$ price increase when merging hospitals are within 5 miles of each other, but not when they are 25 miles or further apart. In a similar vein, Dafny et al. (2019) study the effect of hospital mergers over the 1996-2012 period. Their results indicate acquirers raise their own prices and quality improvements are not the source of the increase. Dafny et al., like Cooper et al., find the price effects are largest when the merging hospitals are in close proximity (30-90 minutes' drive) with each other. More recently, the National Council on Compensation Insurance (NCCI) tracked the price results of recent hospital and hospital system mergers. Their study indicates hospital mergers result in average price growth of $6 \%-18 \%$ for hospital services.

More disturbingly, mergers can have negative price consequences for areas that do not experience merger activity. Schmitt (2018) observes a notable spillover effect for hospital system mergers. Mergers that increase multimarket contact between two hospitals systems result in price increases of $6 \%$ for markets where the merger did not occur. As an illustrative example, imagine there are three hospital systems: Acquirer, Target, and Idle. Prior to the acquisition, Acquirer operates in Market 1, Target operates in Market 2, and Idle operates in Markets 1 and 2.

After Acquirer takes over Target, Acquirer now operates in both Markets 1 and 2 with Idle. Schmitt finds the hospitals in Market 1, where there was no market change, experience the $6 \%$ price increase due to the market consolidation in the other region. Consequently, this finding is highly frightening during this period of increased merger activity.

\section{CONCLUSION}

It appears clear that vertical consolidations will continue to occur across the U.S. healthcare delivery system. In this paper, the authors have not explored the influence of governmental and political decisions that, in recent years, have not attended to the diminishment of antitrust laws, changes in federal versus state regulations, and, perhaps most importantly, the continued enforcement of the Affordable Care Act. Indeed, in an election year, alternative forms of healthcare delivery could influence the ways in which these consolidations are structured and administered. Regardless of these and a myriad of other factors, solid evidence must be made available to prove that current and future mergers deliver what they promise namely, clear communications, quality care outcomes, and reduced costs.

\section{REFERENCES}

Capps, C., Dranove, D., \& Ody, C. (2018). The effect of hospital acquisitions of physician practices on prices and spending. Journal of Health Economics, 59, 139-152.

Cooper, Z., Craig, S. V., Gaynor, M., \& Van Reenen, J. (2018). The price ain't right? Hospital prices and health spending on the privately insured. The Quarterly Journal of Economics, 134(1), 51-107.

Dafny, L., Ho, K., \& Lee, R.S. (2019). The price effects of cross-market mergers: Theory and evidence from the hospital industry. The RAND Journal of Economics, 50(2), 286-325.

Desai, S., \& McWilliams, J.M. (2018). Consequences of the 340B drug pricing program. New England Journal of Medicine, 378(6), 539-548.

Dewar, C., \& Keller, S. (2009, April). The irrational side of change management. McKinsey Quarterly. Retrieved from https:/www.mckinsey.com/business-functions/organization/our-insights/theirrational-side-of-change-management

Ferrell, O.C., Fraedrich, J., \& Ferrell, L. (2018). Business ethics: Ethical decision making and cases (12th Edition). Cengage, 120. 
Findlay, S. (2018, July 23). Can a community hospital stay true to its mission after sale to large corporation? Retrieved from https://www.washingtonpost.com/national/health-science/can-acommunity-hospital-stay-true-to-its-mission-after-sale-to-largecorporation/2018/07/23/e98fc360-8e58-11e8-ae59-01880eac5f1d_story.html

Frakt, A.B. (2015). Hospital consolidation isn't the key to lowering costs and raising quality. JAMA, $313(4), 345$.

Greaney, T.L. (2018). The New Health Care Merger Wave: Does The "Vertical, Good" Maxim Apply? The Journal of Law, Medicine \& Ethics, 46, 920.

Jonas, S., \& Kovner, A.R. (2011). Health care delivery in the United States (10th Edition, pp. 362-363). Springer Publishing Company.

Kaetzler, B., Kordestani, K., O’Loughlin, E., \& Van Oosterde, M. (2019, December). Managing and supporting employees through cultural change in mergers. McKinsey Quarterly, p.1. Retrieved from https://www.mckinsey.com/business-functions/organization/our-insights/managing-andsupporting-employees-through-cultural-change-in-mergers

Katz, J.R., \& Clemons, P. (1995, December). Surviving a merger: How not to come apart when two hospitals come together. Nursing, pp. 40-41.

LaPointe, J. (2019, February 14). Vertical integration in healthcare doesn't boost care quality. Practice Management News, p.1. Retrieved from https://revcycleintelligence.com/news/verticalintegration-in-healthcare-doesnt-boost-care-quality

Melnick, G., \& Keeler, E. (2007). The effects of multi-hospital systems on hospital prices. Journal of Health Economics, 26(2), 400-413.

National Council on Compensation Insurance (2018, July 11). The impact of hospital consolidation on medical costs. Retrieved from https://www.ncci.com/Articles/Pages/II_Insights_QEB_Impact-ofHospital-Consolidation-on-Medical-Costs.aspx

Robert Wood Johnson Foundation. (2014, July 24). Health policy brief: Site-neutral payments. Health Affairs, MedPAC, Report to Congress, 2014.

Schmitt, M. (2018). Multimarket contact in the hospital industry. American Economic Journal: Economic Policy, 10(3), 361-87.

Short, M.N., \& Ho, V. (2020). Weighing the effects of vertical integration versus market concentration on hospital quality. Medical Care Research and Review, 77(6), 538-548.

U.S. Government Accountability Office. (2018, September 28). Rural hospital closures: Number and characteristics of affected hospitals and contributing factors. Retrieved from https://www.gao.gov/products/GAO-18-634 